\title{
Ovarian Seromucinous Borderline Tumors Are Histologically Different from Mucinous Borderline Tumors
}

\author{
TAIRA HADA ${ }^{1}$, MORIKAZU MIYAMOTO $^{1}$, HIROKI ISHIBASHI ${ }^{1}$, HARUKA KAWAUCHI $^{1}$, \\ HIROAKI SOYAMA ${ }^{1}$, HIROKO MATSUURA ${ }^{1}$, TAKAHIRO SAKAMOTO ${ }^{1}$, SOICHIRO KAKIMOTO $^{1}$, \\ TADASHI AOYAMA ${ }^{1}$, HIDEKI IWAHASHI $^{1}$, RIE SUZUKI $^{1}$, HITOSHI TSUDA $^{2}$ and MASASHI TAKANO ${ }^{1}$ \\ ${ }^{1}$ Department of Obstetrics and Gynecology, National Defense Medical College Hospital, Tokorozawa, Japan; \\ ${ }^{2}$ Department of pathology, National Defense Medical College Hospital, Tokorozawa, Japan
}

\begin{abstract}
Aim: To examine the clinicopathological features of ovarian seromucinous borderline tumors (SMBTs) and compare them with those of mucinous borderlinelatypical proliferative mucinous tumors (MB/APMTs). Patients and Methods: Patients with SMBT between 2014 and 2018 and those with MB/APMT between 1988 and 2018 who underwent surgery at our Institution were identified. Pathological review was conducted using the 2014 World Health Organization criteria. Clinical features were compared retrospectively between SMBT and MB/APMT. Results: In total, 11 (12.9\%) patients with SMBT and 74 (87.1\%) patients with MB/APMT were included in our study. The diagnosis of six patients with SMBT and 73 patients with $M B / A P M T$ was not revised on review. SMBT was diagnosed at a younger age $(p=0.04)$, was of smaller size $(p<0.01)$ and bilateral $(p=0.03)$, coexisted with endometriosis $(p<0.01)$, and more frequently recurred than MB/APMT $(p=0.04)$. Conclusion: $S M B T$ might be more aggressive than MB/APMT.
\end{abstract}

Borderline ovarian tumors are those with higher epithelial proliferation than benign ovarian tumors and variable nuclear atypia without destructive stromal invasion in contrast to carcinomas (1). The incidence of borderline ovarian tumors is $10-20 \%$ of all epithelial ovarian tumors $(2,3)$. Patients with these types of tumor have an excellent prognosis, with an overall 10 -year survival rate of $83-91 \%$, which is better than that of patients with ovarian carcinomas $(1,4,5)$.

This article is freely accessible online.

Correspondence to: Morikazu Miyamoto, Department of Obstetrics and Gynecology, National Defense Medical College Hospital, 3-2, Namiki, Tokorozawa, Saitama 359-8513, Japan. Tel: +81 429951678, Fax: +81 429965213, e-mail: morikazu1118@hotmail.co.jp

Key Words: Seromucinous, mucinous, borderline tumors, atypical proliferative mucinous tumors, recurrence, 2014 World Health Organization, prognosis.
In the 2014 World Health Organization (WHO) classification, seromucinous borderline tumors (SMBTs) were newly classified (6). According to these criteria, SMBTs have architectural features similar to those of serous borderline tumors and exhibit complex papillary architecture branching, in a hierarchical manner, into progressively smaller papillae, terminating in small detached epithelial tufts. The larger papillae tend to have edematous stroma containing neutrophils. The epithelium lining the papillae is typically stratified and composed mostly of endocervicaltype mucinous or serous epithelium. Goblet cells are not present. Cytoplasmic eosinophilia is often conspicuous, the nuclei are low grade, and mitotic figures are infrequent. However, since the publication of the 2014 WHO classification, not much clinical and pathological information about SMBT has been reported.

Thus, this study aimed to examine the clinicopathological features of SMBTs and compare them with those of mucinous borderline/atypical proliferative mucinous tumors (MB/APMTs) through a pathological review.

\section{Patients and Methods}

Patients with SMBT between 2014 and 2018 and MB/APMT between 1988 and 2018 who underwent surgery at our hospital were identified. Pathological review was conducted using the $2014 \mathrm{WHO}$ criteria (6). SMBT was defined as a non-invasive, proliferative, epithelial tumor composed of more than one epithelial cell type, most often serous and endocervical-type mucinous, with or without microinvasion defined as small foci of stromal invasion measuring $<5 \mathrm{~mm}$ in the greatest linear extent. In addition, tumors comprising $>90 \%$ SMBTs in the entire borderline tumoral area were included as SMBTs but tumors with even small foci of other borderline tumors such as clear-cell borderline tumor were excluded from our study. Moreover, MB/APMT was defined as a tumor composed of mild-to-moderately atypical gastrointestinal-type, mucin-containing epithelial cells. The cells were in the form of gastric pyloric-type epithelium, goblet cells, neuroendocrine cells, and Paneth cells, with proliferation greater than that seen in benign mucinous tumors, with or without microinvasion defined as small foci of stromal invasion 

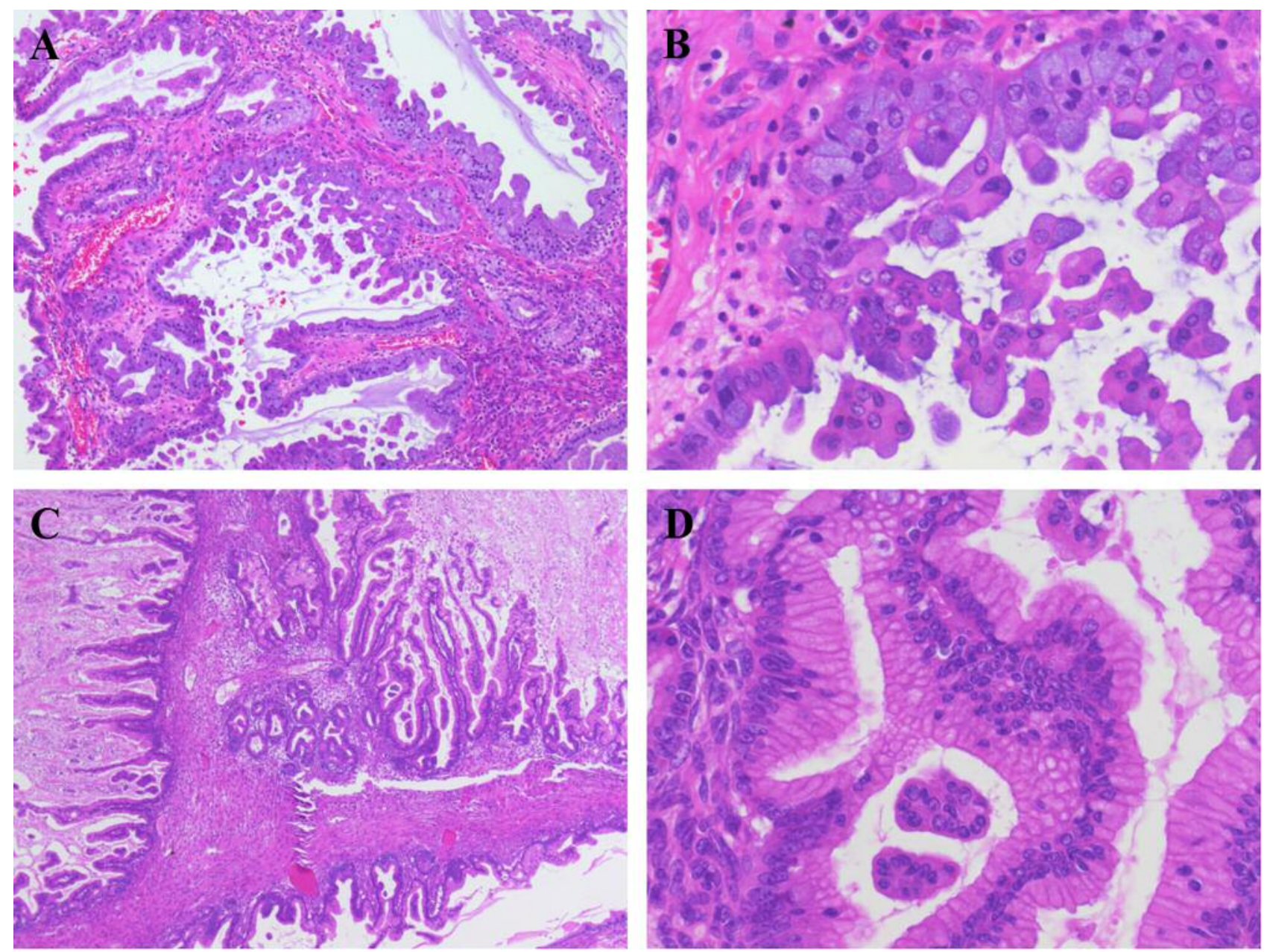

Figure 1. Representative images of seromucinous borderline tumors (SMBT) and mucinous borderline tumors/atypical proliferative mucinous tumors $(M B / A P M T)$. A: SMBT demonstrating papillary architecture with hierarchial branching $(\times 40)$. B: Branching papillae of SMBT are lined by varying proportions of endocervical-type mucinous, tubal-type serous, and indeterminate cells with dense eosinophilic cytoplasm ( $\times 400)$. C: MB/APMT demonstrating cystic glandular structures with papillary infoldings, columnar cells with abundant cytoplasmic mucin, admixed with goblet cells of variable degrees of maturation (x100). D: Basally located nuclei with no considerable nuclear atypia are seen in MB/APMT (x400).

\begin{tabular}{|c|c|c|}
\hline $\begin{array}{c}\text { Histological type before } \\
\text { pathological review }\end{array}$ & $\begin{array}{l}\text { Histological type after } \\
\text { pathological review }\end{array}$ & $\begin{array}{l}\text { Included cases }(\mathrm{n}=85) \\
\text { Seromucinous borderline tumor }(\mathrm{n}=11)\end{array}$ \\
\hline \multicolumn{2}{|l|}{ All cases $(\mathrm{n}=89)$} & Mucinous borderline tumor $(n=74)$ \\
\hline Seromucinous borderline tumor $(\mathrm{n}=11)$ & $\begin{array}{l}\text { Seromucinous borderline tumor }(\mathrm{n}=6) \\
\text { Serous borderline tumor }(\mathrm{n}=2) \\
\text { Mucinous borderline tumor }(\mathrm{n}=1) \\
\text { Endometrioid borderline tumor }(\mathrm{n}=1) \\
\text { Seromucinous borderline tumor with } \\
5 \% \text { of clear-cell borderline tumor }(\mathrm{n}=1)\end{array}$ & $\begin{array}{l}\text { Excluded cases }(\mathrm{n}=4) \\
\text { Serous borderline tumor }(\mathrm{n}=2) \\
\text { Endometrioid borderline tumor }(\mathrm{n}=1) \\
\text { Seromucinous borderline tumor with }\end{array}$ \\
\hline Mucinous borderline tumor $(\mathrm{n}=78)$ & $\begin{array}{l}\text { Mucinous borderline tumor }(\mathrm{n}=73) \\
\text { Seromucinous borderline tumor }(\mathrm{n}=5)\end{array}$ & $5 \%$ of clear-cell borderline tumor $(n=1)$ \\
\hline
\end{tabular}

Figure 2. Changes of histological type of cases through the pathological review. Eighty-nine patients with seromucinous and mucinous borderline tumors/atypical proliferative mucinous tumors were identified. Among them, two with serous borderline tumors, one with endometrioid borderline tumor, and one with seromucinous borderline tumor with 5\% clear-cell borderline tumor were excluded. Finally, 11 patients with seromucinous borderline tumors and 74 patients with mucinous borderline tumors/atypical proliferative mucinous tumors were included. 
measuring $<5 \mathrm{~mm}$ in the greatest linear extent. Representative images of SMBT and MB/APMT are shown in Figure 1. Finally, patients with SMBT and MB/APMT were included in our study. Patients without medical information and surgical tissue were excluded.

Clinical information was obtained from medical records. Staging was re-evaluated by 2014 International Federation of Gynecology and Obstetrics (FIGO) criteria (7). Progression-free survival (PFS) was defined as the period from the day of first surgery to the day of recurrence. Overall survival (OS) was defined as the period from the day of first surgery to the day of last contact alive. Standard surgery was defined as bilateral salpingo-oophorectomy with hysterectomy, omentectomy, or multiple peritoneal biopsy and lymphadenectomy, whereas fertility-sparing surgery was defined as unilateral salpingo-oophorectomy and cystectomy or bilateral cystectomy with or without omentectomy, peritoneal biopsy, and lymphadenectomy.

Statistical analysis was performed using the JMP Pro 14 software (SAS Institute Inc., Cary, NC, USA). The chi-squared test, Fisher's exact test, Mann-Whitney $U$-test, and Wilcoxon test were used to evaluate the significance of clinical factors. Statistical significance was defined as a value of $p<0.05$.

This study was approved by the Clinical Research Ethics Committee of the National Defense Medical College (no. 3022).

\section{Results}

A total of 89 patients with SMBT between 2014 and 2018 or MB/APMT between 1988 and 2018 diagnosed at our hospital were identified. The results of pathological review are shown in Figure 2. Among 11 patients with SMBT before pathological review, the diagnosis of six patients was not changed, but that for five patients was changed from SMBT to other subtypes: two patients had serous borderline tumors, one patient had MB/APMT, one had endometrioid borderline tumor, and one had SMBT with 5\% clear-cell borderline tumor. Among 78 patients with MB/APMT before pathological review, the diagnosis of 73 patients was not changed but that of five patients was changed from MB/APMT to SMBT. Finally, 11 patients with SMBT and 74 patients with MB/APMT were included in our analysis.

The clinical and pathological characteristics of SMBT and MB/APMT are presented in Table I. In general, SMBT was diagnosed at a younger age $(p=0.04)$, was of smaller tumor size $(p<0.01)$, more frequently observed in bilateral ovaries $(p=0.03)$, and coexisted with endometriosis $(p<0.01)$ compared to MB/APMT. Moreover, patients with SMBT were more likely to experience recurrence than those with MB/APMT ( $p=0.04)$. There were no statistically significant differences in terms of PFS $(p=0.56)$ and OS $(p=0.76)$ between patients with SMBT and those with MB/APMT. The recurrence rate for patients with SMBT who underwent hysterectomy with unilateral salpingo-oophorectomy and multiple peritoneal biopsy, bilateral salpingo-oophorectomy, and cystectomy was $0 \%(0 / 50), 25 \%(1 / 5)$, and $100 \%(1 / 1)$, respectively. The recurrence rate for patients with
Table I. Comparison of clinical and pathological characteristics between patients with seromucinous borderline tumors (SMBT) and those with mucinous borderlinelatypical proliferative mucinous tumors $(M B / A P M T)$.

\begin{tabular}{|c|c|c|c|}
\hline Clinical factor & $\begin{array}{l}\text { SMBT } \\
(\mathrm{n}=11)\end{array}$ & $\begin{array}{c}\mathrm{MB} / \mathrm{APMT} \\
(\mathrm{n}=74)\end{array}$ & $p$-Value \\
\hline \multicolumn{4}{|l|}{ Age, years } \\
\hline Mean \pm SD & $39.9 \pm 14.2$ & $51.4 \pm 17.9$ & 0.04 \\
\hline$<40$ Years & $6(54.5)$ & $20(27.0)$ & \multirow[t]{2}{*}{0.08} \\
\hline$\geq 40$ Years & $5(45.5)$ & $54(73.0)$ & \\
\hline \multicolumn{4}{|l|}{ Stage, n (\%) } \\
\hline I & $11(100)$ & $72(97.3)$ & \multirow[t]{4}{*}{0.99} \\
\hline II & $0(0.0)$ & $0(0.0)$ & \\
\hline III & $0(0.0)$ & $2(2.7)$ & \\
\hline IV & $0(0.0)$ & $0(0.0)$ & \\
\hline \multicolumn{4}{|l|}{ Tumor size, $\mathrm{cm}$} \\
\hline Mean \pm SD & $8.9 \pm 3.6$ & $18.1 \pm 7.3$ & $<0.01$ \\
\hline \multicolumn{4}{|l|}{ Site of tumor, n (\%) } \\
\hline Unilateral & $8(72.7)$ & $71(96.0)$ & \multirow[t]{2}{*}{0.03} \\
\hline Bilateral & $3(27.3)$ & $3(4.0)$ & \\
\hline \multicolumn{4}{|c|}{ Endometriosis, n (\%) } \\
\hline Yes & $6(54.5)$ & $8(10.8)$ & \multirow[t]{2}{*}{$<0.01$} \\
\hline No & $5(45.5)$ & $66(89.2)$ & \\
\hline \multicolumn{4}{|l|}{ Surgical type, n (\%) } \\
\hline Standard & $5(45.5)$ & $39(52.7)$ & \multirow[t]{2}{*}{0.75} \\
\hline Fertility-sparing & $6(54.5)$ & $35(47.3)$ & \\
\hline \multicolumn{4}{|c|}{$\begin{array}{l}\text { Adjuvant } \\
\text { chemotherapy, n (\%) }\end{array}$} \\
\hline Yes & $0(0.0)$ & $2(2.7)$ & \multirow[t]{2}{*}{0.99} \\
\hline No & $11(100)$ & $72(97.3)$ & \\
\hline \multicolumn{4}{|l|}{ Recurrence, n (\%) } \\
\hline Yes & $2(18.2)$ & $1(1.4)$ & \multirow[t]{2}{*}{0.04} \\
\hline No & $9(81.1)$ & 73 (98.6) & \\
\hline \multicolumn{4}{|l|}{ PFS, months } \\
\hline Mean \pm SD & $56.8 \pm 46.7$ & $68.5 \pm 54.8$ & 0.56 \\
\hline \multicolumn{4}{|l|}{ OS, months } \\
\hline Mean \pm SD & $75.3 \pm 80.1$ & $68.5 \pm 54.8$ & 0.76 \\
\hline
\end{tabular}

SD: Standard deviation; PFS: performance-free survival; OS: overall survival. Standard surgery: Bilateral salpingo-oophorectomy with hysterectomy, omentectomy, or multiple peritoneal biopsy and lymphadenectomy. Fertility-sparing surgery: Unilateral salpingooophorectomy and cystectomy or bilateral cystectomy with or without omentectomy, peritoneal biopsy, and lymphadenectomy.

MB/APMT who underwent hysterectomy with unilateral salpingo-oophorectomy and multiple peritoneal biopsy, bilateral salpingo-oophorectomy, and cystectomy was 2.6 $(1 / 39), 0 \%(0 / 32)$, and $0 \%(0 / 3)$, respectively.

The clinical and pathological characteristics of the 11 patients with SMBT are shown in Table II. Among the 11 patients with SMBT, two experienced recurrence. In the first case, the patient was 28 years old. She had undergone bilateral cystectomy as first surgery. Pathological examination revealed her disease was SMBT at FIGO stage IC3. At 83 months after the first surgery, her disease recurred at both ovaries and she underwent left salpingo- 
in vivo $34: 1341-1346(2020)$

Table II. Clinical and pathological characteristics of 11 patients with seromucinous borderline tumors.

\begin{tabular}{|c|c|c|c|c|c|c|c|c|c|c|c|c|}
\hline $\begin{array}{l}\text { Age, } \\
\text { years }\end{array}$ & Parity & Stage & $\begin{array}{l}\text { Tumor } \\
\text { size } \\
(\mathrm{cm})\end{array}$ & $\begin{array}{l}\text { Site of } \\
\text { tumor }\end{array}$ & Surgical type & Endometriosis & Recurrence & $\begin{array}{l}\text { Time to } \\
\text { recurrence } \\
\text { (Months) }\end{array}$ & $\begin{array}{l}\text { Recurrence } \\
\text { site }\end{array}$ & $\begin{array}{l}\text { Surgery } \\
\text { after } \\
\text { recurrence }\end{array}$ & $\begin{array}{l}\text { Follow-up } \\
\text { period } \\
\text { (months) }\end{array}$ & $\begin{array}{l}\text { Status } \\
\text { at the end } \\
\text { of study }\end{array}$ \\
\hline 26 & Primipara & IA & 16 & Right & RSO+left cystectomy & Yes & No & & & & 15 & NED \\
\hline 27 & Primipara & IA & 7 & Left & LSO+peritoneal biopsy & Yes & No & & & & 130 & NED \\
\hline 28 & Primipara & IC3 & 5 & Bilateral & Bilateral cystectomy & Yes & Yes & 83 & $\begin{array}{c}\text { Bilateral } \\
\text { ovaries }\end{array}$ & $\begin{array}{l}\text { LSO+right } \\
\text { cystectomy }\end{array}$ & 148 & NED \\
\hline 29 & Primipara & IC1 & 10 & Right & $\begin{array}{l}\text { RSO+omentectomy+ } \\
\text { lymphadenectomy }\end{array}$ & No & No & & & & 13 & NED \\
\hline 31 & Multipara & IC2 & 5.5 & Right & $\begin{array}{c}\text { RSO+omentectomy+ } \\
\text { peritoneal biopsy+ } \\
\text { lymphadenectomy }\end{array}$ & Yes & No & & & & 23 & NED \\
\hline 32 & Primipara & IA & 15 & Left & LSO+peritoneal biopsy & No & Yes & 127 & Right & RSO & 265 & NED \\
\hline 41 & Primipara & IA & 8 & Left & $\begin{array}{l}\mathrm{BSO}+\mathrm{TAH}+\text { omentectomy+ } \\
\text { lymphadenectomy }\end{array}$ & No & No & & ovary & & 7 & NED \\
\hline 48 & Multipara & IA & 7 & Left & $\begin{array}{c}\mathrm{BSO}+\mathrm{TAH}+\text { omentectomy+ } \\
\text { lymphadenectomy }\end{array}$ & Yes & No & & & & 46 & NED \\
\hline 51 & Primipara & IB & 6.3 & Bilateral & $\mathrm{BSO}+\mathrm{TAH}+$ omentectomy & Yes & No & & & & 17 & NED \\
\hline 62 & Multipara & IB & 9 & Bilateral & BSO+TAH+omentectomy & No & No & & & & 65 & NED \\
\hline 64 & Multipara & IA & 9 & Right & BSO+TAH+omentectomy & No & No & & & & 99 & NED \\
\hline
\end{tabular}

BSO: Bilateral salpingo-oophorectomy; LSO: left salpingo-oophorectomy; NED: no evidence of disease; RSO: right salpingo- oophorectomy; TAH: total abdominal hysterectomy.

oophorectomy and right cystectomy. For 65 months from the second surgery, her disease did not progress. The second case was 32 years old. She underwent left salpingooophorectomy as the first surgery. Pathological examination revealed her disease to be SMBT FIGO stage IA. Her disease recurred at the right ovary at 127 months from the first surgery, and she underwent right salpingo-oophorectomy. She was alive with no evidence of disease for 138 months from the second surgery.

The characteristics of the patient with MB/APMT who experienced recurrence are described as follows. The patient was 57 years old. She underwent bilateral salpingooophorectomy with hysterectomy and omentectomy as the first surgery. Pathological examination confirmed the diagnosis of FIGO stage IIIB MB/APMT. At 100 months from the first surgery, her disease recurred at the sigmoidal colonic surface and she underwent sigmoidal colectomy. For 5 months from the second surgery, her disease did not progress.

\section{Discussion}

In this study, we found that SMBT was diagnosed at a younger age, was of smaller size, and was more frequently observed in bilateral ovaries or co-existed with endometriosis compared to MB/APMT.

Previous reports showed that the incidence of SMBT in MB/APMT ranged from $12.9 \%$ to $15.2 \%$ through pathological review for MB/APMT (8-10). In our study, the incidence of SMBT was slightly lower. The pathological diagnosis of SMBT and MB/APMT was easily distinguished using hematoxylin and eosin-stained sections as performed in routine practice (11). However, the diagnosis for the cases with the columnar mucinous gastric foveolar-type epithelium in pure gastrointestinal type tumors is difficult and for this reason immunohistochemical analysis may at times be required. Compared to MB/APMTs, SMBTs were positive for estrogen receptor, progesterone receptor and vimentin, and were negative for cytokeratin $20(11,12)$. Fortunately, because our study did not include cases that were difficult to diagnose as mentioned above, immunochemical analysis was not performed.

Previous reports showed that SMBT was diagnosed at an average age of 34-42 years, developed in both ovaries in $16 \%$ to $40 \%$ of cases, and produced tumors with a mean size of 8-11 cm (8, 13-15). Pathologically, SMBTs were characterized by their variety in cell composition and coexisted with endometriosis in $30-70 \%$ of patients $(16,17)$. In addition, the reported recurrence rate of SMBT was 5$28.6 \%(18-20)$. In previous reports, compared with MB/APMT, SMBT occurred more often in younger women (8), was more often bilateral $(8,21,22)$, smaller $(8,21,22)$, and more frequently associated with endometriosis $(8,21$, 22 ). The findings of our study are consistent with those in previous reports.

There are arguments over the prognosis and recurrence rate for SMBT and MB/APMT $(8,9,18,19)$. In our study, the recurrence rate of SMBT was higher than that of MB/APMT. One of the factors associated with prognosis and recurrence 
was the surgical method used. The recurrence rate in patients with all borderline ovarian tumors who underwent hysterectomy with bilateral salpingo-oophorectomy and multiple peritoneal biopsy, bilateral salpingo-oophorectomy, unilateral salpingo-oophorectomy, and cystectomy was 2.5$5.7 \%, 0-20 \%, 0-67 \%$, and $12-58 \%$, respectively $(23,24)$. In our study, because two patients with recurrence underwent unilateral salpingo-oophorectomy or cystectomy, fertilitypreserving surgery for patients with SMBT may have increased the recurrence rate. Thus, the choice of surgical procedure needs to be carefully evaluated in patients with SMBT. However, preservation of fertility for patients with SMBT was important because SMBT developed at a relatively younger age. Fortunately, our study showed that the time from first surgery until recurrence was long even if unilateral salpingo-oophorectomy and cystectomy were performed. Moreover, the site of recurrence was limited to the ovary and the recurrence was not fatal. Therefore, fertility-preserving surgery might be permissible for patients with SMBT. In such cases, close examination of the preserved ovary might be needed.

In contrast, SMBT has a histology associated with endometriosis-related ovarian neoplasms similar to ovarian clear-cell carcinoma and endometrioid carcinoma. As a result, loss of ARID1A staining was reportedly observed in $33 \%$ of cases SMBT (17). The rate of mutation of ARIDIA in clear-cell carcinoma and endometrioid carcinoma were $50 \%$ and $40 \%$, respectively $(17,25)$. SMBTs might have a molecular profile more similar to that of clear-cell carcinoma or endometrioid carcinoma. In our study, SMBT was positively associated with endometriosis. Thus, this might have increased the recurrence rate.

The limitations of this study include its small sample size at a single-institution, and being a retrospective analysis. Further studies with a large sample size are needed to confirm the clinical significance of SMBT.

In conclusion, through pathological reviews we found that SMBT developed at a relatively younger age, in both ovaries, was complicated by endometriosis, and more often recurred compared with MB/APMT. Therefore, SMBT might have different characteristics from MB/APMT. Further large-scale studies examining this in detail are needed.

\section{Conflicts of Interest}

The Authors declare that they have no conflicts of interest.

\section{Authors' Contributions}

Conception and design: TH, MM, and MT. Analysis and interpretation of data: TH, MM, HI, HK, HS, HM, TS, SK, TA, HI, RS and HT. Drafting of the article or revision: TH, MM, and MT.

\section{Acknowledgements}

The Authors would like to thank Ayako Suzuki for collecting samples and Editage (www.editage.com) for English language editing.

\section{References}

1 Prat J: Pathology of borderline and invasive cancers. Best Pract Res Clin Obstet Gynaecol 41: 15-30, 2017. PMID: 28277307. DOI: 10.1016/j.bpobgyn.2016.08.007

2 Dewilde K, Moerman P, Leunen K, Amant F, Neven P and Vergote I: Staging with unilateral salpingo-oophorectomy and expert pathological review result in no recurrences in a series of 81 intestinal-type mucinous borderline ovarian tumors. Gynecol Obstet Invest 83(1): 65-69, 2018. PMID: 28689208. DOI: 10.1159/000478929

3 Tinelli R, Tinelli A, Tinelli FG, Cicinelli E and Malvasi A: Conservative surgery for borderline ovarian tumors: A review. Gynecol Oncol 100(1): 185-191, 2006. PMID: 16216320. DOI: 10.1016/j.ygyno.2005.09.021

4 Song T, Hun Choi C, Lee YY, Kim TJ, Lee JW, Bae DS and Kim BG: Oncologic and reproductive outcomes of cystectomy compared with oophorectomy as a treatment for borderline ovarian tumours. Hum Reprod 26(8): 2008-2014, 2011. PMID: 21511712. DOI: $10.1093 /$ humrep/der119

5 Song T, Lee YY, Choi CH, Kim TJ, Lee JW, Bae DS and Kim BG: Borderline ovarian tumor in women aged $\geq 65$ years: Impact on recurrence and survival. Eur J Obstet Gynecol Reprod Biol 184: 38-42, 2015. PMID: 25463633. DOI: 10.1016/j.ejogrb. 2014.10.001

6 Kurman RJ, Carcangiu ML, Herrington CS and Young RH: WHO Classification of Tumours of Female Reproductive Organs. Fourth Edition. Lyon, International Agency for Research Cancer, pp. 25-40, 2014.

7 Pereira A, Perez-Medina T, Margrina JF, Magtibay PM, Rodriguez-Tapia A, Peregrin I, Mendizabal E and OrtizQuintana L: International Federation of Gynecology and Obstetrics staging classification for cancer of the ovary, fallopian tube, and peritoneum: Estimation of survival in patients with node-positive epithelial ovarian cancer. Int J Gynecol Cancer 25(1): 49-54, 2015. PMID: 25405578. DOI: 10.1097/IGC. 0000000000000316

8 Rutgers JL and Scully RE: Ovarian Mullerian mucinous papillary cystadenomas of borderline malignancy. A clinicopathologic analysis. Cancer 61(2): 340-348, 1988. PMID: 3334969. DOI: 10.1002/1097-0142(19880115)61:2<340::aidcncr2820610225>3.0.co;2-u

9 Koakas M, Uzan C, Gouy S, Pautier P, Lhomme C, Haie-Meder C, Duvillard P and Morice P: Prognostic factors of a large retrospective series of mucinous borderline tumors of the ovary (excluding peritoneal pseudomyxoma). Ann Surg Oncol 18(1): 4048, 2011. PMID: 20737216. DOI: 10.1245/s10434-010-1293-8

10 Nomura $\mathrm{K}$ and Aizawa S: Clinicopathologic and mucin histochemical analyses of 90 cases of ovarian mucinous borderline tumors of intestinal and Mullerian types. Pathol Int 46(8): 575-580, 1996. PMID: 8893226. DOI: 10.1111/j.14401827.1996.tb03656.x

11 Vang R, Gown AM, Barry TS, Wheeler DT and Ronnett BM: Ovarian atypical proliferative (borderline) mucinous tumors: 
gastrointestinal and seromucinous (endocervical-like) types are immunophenotypically distinctive. Int J Gynecol Pathol 25(1): 83-89, 2006. PMID: 16306790. DOI: 10.1097/01.pgp. 0000177125.31046.fd

12 Yasunaga M, Ohishi Y, Oda M, Misumi M, Iwasa A, Kurihara $\mathrm{S}$, Nishimura I, Okuma E, Kobayashi $\mathrm{H}$, Wake $\mathrm{N}$ and Tsuneyoshi M: Immunohistochemical characterization of Mullerian mucinous borderline tumors: Possible histogenetic link with serous borderline tumors and low-grade endometrioid tumors. Hum Pathol 40(7): 965-974, 2009. PMID: 19269675. DOI: $10.1016 /$ j.humpath.2008.12.006s

13 Dube V, Roy M, Plante M, Reunaud MC and Tetu B: Mucinous ovarian tumors of Mullerian-type: An analysis of 17 cases including borderline tumors and intraepithelial, microinvasive, and invasive carcinomas. Int J Gynecol Pathol 24(2): 138-146, 2005. PMID: 15782070. DOI: 10.1097/01.pgp.0000152024. 37482.63

14 Rodriguez IM, Irving JA and Prat J: Endocervical-like mucinous borderline tumors of the ovary: A clinicopathologic analysis of 31 cases. Am J Surg Pathol 28(10): 1311-1318, 2004. PMID: 15371946. DOI: 10.1097/01.pas.0000138178.10829.b8

15 Shappell HW, Riopel MA, Smith Sehdev AE, Ronnett BM and Kurman RJ: Diagnostic criteria and behavior of ovarian seromucinous (endocervical-type mucinous and mixed cell-type) tumors: Atypical proliferative (borderline) tumors, intraepithelial, microinvasive, and invasive carcinomas. Am J Surg Pathol 26(12): 1529-1541, 2002. PMID: 12459620. DOI: 10.1097/00000478-200212000-00001

16 Karpathiou G, Chauleur C, Corsini T, Venet M, HabougitC, Honeyman F, Forest F and Peoc'h M: Seromucinous ovarian tumor A comparison with the rest of ovarian epithelial tumors. Ann Diagn Pathol 27: 28-33, 2017. PMID: 28325358. DOI: 10.1016/j.anndiagpath.2017.01.002

17 Maeda D and Shih IM: Pathogenesis and the role of ARID1A mutation in endometriosis-related ovarian neoplasms. Adv Anat Pathol 20(1): 45-52, 2013. PMID: 23232571. DOI: 10.1097/ PAP.0b013e31827bc24d

18 Sun $\mathrm{L}$, Li N, Song $\mathrm{Y}$, Wang $\mathrm{G}$, Zhao $\mathrm{Z}$ and $\mathrm{Wu} \mathrm{L}$ : Clinicopathologic features and risk factors for recurrence of mucinous borderline ovarian tumors: A retrospective study with follow-up of more than 10 years. Int J Gynecol Cancer 28(9): 1643-1649, 2018. PMID: 30365456. DOI: 10.1097/IGC 0000000000001362
19 Sun L, Song Y, Li N, Yuan GW, Sun YC, Li N, Ma SK, Zhang $\mathrm{X}$ and $\mathrm{Wu} \mathrm{LY}$ : The clinicopathological features and risk factors of recurrence in patients with mucinous borderline ovarian tumors. Zhonghua Zhong Liu Za Zhi 39(8): 589-594, 2017. PMID: 28835081. DOI: 10.3760/cma.j.issn.0253-3766.2017. 08.006

20 Black JD, Altwerger GH, Ratner E, Lu L, Silasi DA, Azodi M, Santin DS, Schwartz PE and Rutherford TJ: Management of borderline ovarian tumors based on patient and tumor characteristics. Gynecol Obstet Invest 81: 169-173, 2016. PMID: 26067608. DOI: $10.1159 / 000431219$

21 Song T, Choi CH, Lee YY, Kim TJ, Lee JW, Sung CO, Song SY Bae DS and Kim BG: Endocervical-like versus intestinal-type mucinous borderline ovarian tumors: a large retrospective series focusing on the clinicopathologic characteristics. Gynecol Obstet Invest 76(4): 241-247, 2013. PMID: 24192519. DOI: 10.1159/ 000356072

22 Woo S, Kim SH, Kim MA, Park IA, Lee SY and Cho JY: Magnetic resonance imaging findings of mucinous borderline ovarian tumors: Comparison of intestinal and endocervical subtypes. Abdom Imaging 40(6): 1753-1760, 2015. PMID: 25504376. DOI: 10.1007/s00261-014-0325-4

23 Trope CG, Kaerm J and Davidson B: Borderline ovarian tumours. Best Pract Res Clin Obstet Gynaecol 26(3): 325-336, 2012. PMID: 22321906. DOI: 10.1016/j.bpobgyn.2011.12.006

24 Vasconcelos I and de Sousa Mendes M: Conservative surgery in ovarian borderline tumors: A meta-analysis with emphasis on recurrence risk. Eur J Cancer 51(5): 620-631, 2015. PMID: 25661104. DOI: 10.1016/j.ejca.2015.01.004

25 Guan B, Mao TL, Panuganti PK, Kuhn E, Kurman RJ, Maeda D, Chen E, Jeng YM, Wang TL and Shih IM: Mutation and loss of expression of ARID1A in uterine low-grade endometrioid carcinoma. Am J Surg Pathol 35(5): 625-632, 2011. PMID: 21412130. DOI: 10.1097/PAS.0b013e318212782a 